\title{
O MUNDO DO PODER E 0 PODER DA PALAVRA: UMA LEITURA DA FICÇÃO DE DON DELILLLO
}

REFERRELIAS BIBLIOGRÁFICAS

FOUCAULI, M. Discipline ond punish: the birth of the prison. Ironsl. Alan Sheridon. Harmondsworth, London: Penguin, 1977;

FOUCAULI, Michel. L'Usoged des plaisis. Vol. 2. Histoire de lo sexualitre. Paris: Editions Gollimard, 1984

NORRIS, Christopher. What's wrong with postmodernism: critical theory ond the ends of philosophy. New York. Horvester Wheotsheat 1990

NORRIS, Christopher. Spinozo and the origins of modern critical theory. Oxford: Basil Blockwell, 1991.

WORRS, Christopher. Uncriticol theory: possmodernism, intellectuals and the Gulf War. London: Lowrence and Wishart, 1992. WRRIS, chistophe. The to thour postmodemism. Oxard: Basil Blockwell, 1993.

WRRS,

(1960.

SHARMAN, Adom. A ruse of reason: constitutionalist powers in the work of Michel Fouccoult. Nottingham: The University of Nottinghom, 1985. (unpublished PhD thesis).

\begin{abstract}
Tom Burns
UFMG
\end{abstract}

\section{RESUMO}

Este trabalho analisa alguns textos do romancista contemporâneo Don DeLillo, cuja obra Paul Auster diz ser fundamental para compreender a sociedade norte-americana neste fim de século. Nele pretende-se assinalar a natureza dos temas de sua obra e a relevância dos mesmos para um mundo globalizado, destacando-se os tópicos sobre o poder militar, o terrorismo e o poder do capital, tratando, em especial, a hegemonia das linguagens do poder e a resistência a elas. PALAVRASCHAVES:

ficção, poder, terrorismo, linguagems.

I

As primeiras obras de Don DeLillo foram publicadas no início da década de setenta, mas ganharam espaço no mundo acadêmico apenas nos anos oitenta. Atualmente, DeLillo vem se impondo a cada dia como o romancista norte-americano mais afinado com a história do seu tempo, uma primazia até então reservada a Thomas Pynchon. DeLillo tem constantemente reafirmado que o poder no mundo contemporâneo é invisível e mutável; seus escritos têm repetidamente apontado as conexões entre linguagem e poder, bem como a conflitante interação existente entre esses dois elementos. 
Como demonstrou Foucault, aqueles que têm o controle da palavra têm também o poder tanto de construir quanto de minar identidades sociais.' $\mathrm{O}$ interesse de DeLillo é resistir às tendências de certas linguagens a usurpar o caráter livre da linguagem e sua abertura a múltiplas possibilidades, para imporlhe uma indesejável variante monodiscursiva, que é análoga a e, de certa forma, cúmplice de sistemas políticos de controle e dominação. Seus romances propõem freqüentemente estratégias alternativas, ilustrando, assim, a heteroglossia bakhtiniana, teoria segundo a qual os textos produzem conflitos entre discursos que competem entre si e que tanto podem se colocar lado a lado, quanto se inter-relacionar, suplementar ou contradizer.

DeLillo tenta identificar as radicais mudanças estruturais na nossa era de consumo/informação, denominada por Fredric Jameson o estágio mundial do capitalismo tardio, época "cujo princípio de inteligibilidade estrutural é, pela primeira vez, virtualmente, completamente invisível aos sujeitos individuais cujas vidas organiza". A América de DeLillo é repleta não só de coisas, mas também de simulacros, e é menos um lugar do que um sistema de códigos que determinam e controlam a consciência das pessoas. A metrópole pós-moderna é, tal qual em Pynchon, o campo da ação: Elsewhere [Um Outro Lugar], sua cidade ficcional, constitui um espaço mapeado não só "geograficamente na imaginação popular da era modernista", mas também "geologicamente, como o segmento subterrâneo de um circuito político e econômico global, o mundo da conspiração". ${ }^{3}$ O resultado é a paranóia generalizada de uma sociedade de policiamento quase total. Como diz uma de suas personagens, "Quando a tecnologia alcança um certo nível, as pessoas começam a se sentir como se fossem criminosas... Os fatos sobre você e toda sua existência já se encontram coletados".4

A preocupação de DeLillo com os meios de comunicação de massa e sua linguagem mostra-se evidente desde seu primeiro romance, Americana (1971), até o mais conhecido White Noise (1985). Americana analisa a relação entre consciência privada e sistemas de mídia ao contar a história de David Bell - o próprio nome remete às companhias telefônicas - um executivo de televisão em Nova Iorque, que atravessa o país para fazer um filme sobre seu passado. $O$ filme, enquanto representação, complica-se pelo fato de ser visto

1. POSTER, 1993. p. 79-80; GUARESHI et oliii,15.

2. JAMESON, 1984 . p. 116.

3. MCCLURE, 1991. p. 105.

4. DELlllo, 1978. p. 93; SHAPIRO, 1992. p. 129.

somente através de uma descrição verbal feita por Bell em um livro que ele está escrevendo no momento - livro este que também estamos lendo - sobre seu passado, num movimento tanto espacial (ele escreve de algum lugar fora do país) quanto temporal (a reconstituição por escrito se dá anos depois do filme, que, por sua vez, é realizado anos depois dos eventos). Além disso, o filme retrata somente em parte os eventos da vida de Bell, já que outros são imaginados ou improvisados sob sua direção. $O$ resultado é uma narrativa que faz uso constante da tecnologia, que condiciona tanto a personagem quanto sua cultura.

Quando vai do meio-oeste para o extremo-oeste, contudo, Bell dá-se conta de que a vida competitiva, hierárquica e alienada dos executivos de televisão de Nova Iorque difere em estilo, porém não em essência, daquela que os pilotos de teste, que ele fica conhecendo no Texas, levam, especialmente em relação a bebida e sexo. A própria pista de corrida, como diz Tom LeClair, talvez seja uma metáfora da rotina tumultuada que Bell pensou haver abandonado. ${ }^{5} \mathrm{~A}$ pista é o espaço do automóvel, como a rede é o da televisão, dois bens de consumo diferentes que vêm transformando o espaço do país: o primeiro, literalmente, e o segundo, eletronicamente. $O$ automóvel permitiu às pessoas explorarem o país, porém também contribuiu para arruiná-lo: os beats de Kerouac em On the Road dependem de carros e o próprio Bell está vivendo uma típica viagem espiritual. A televisão, por sua vez, transformou as pessoas de sujeitos em busca permanente, às vezes, agressiva, em consumidores essencialmente passivos por meio da invasão de suas transmissões unilaterais, vistas por William S. Burroughs em Naked Lunch como a essência do controle. Há nisso um paralelo tanto simbólico quanto econômico, pois "a indústria da televisão produz mensagens do mesmo modo que os fabricantes de veículos produzem bens". ${ }^{6}$ A própria comunicação está a serviço de bens de consumo, uma vez que a TV existe principalmente para vender produtos, e seus comerciais, na verdade são mais importantes do que os programas, como admite o pai de Bell.

Baudrillard descreve essa situação como a transformação de uma sociedade em que o modo de produção é dominante em uma sociedade em que o código de produção se torna primário (grifo meu ${ }^{7}$. A produção de signos substitui a produção de objetos, o que resulta numa perda de valor para os próprios produtos, que, no que diz respeito à televisão, são intercambiáveis. Isso faz com que "Solilóquio", programa em que Bell apresenta pessoas falando

5. LECLAIR, 1987. p. 48

6. LECLAIR, op. tit., p. 47

7. KELLNER, 1989. p. 61. 
sobre suas vidas numa tentativa de transmissão de valores humanos, seja cancelado. Pessoas reais vêm em segundo lugar em relação a comerciais, como é mostrado na própria família de Bell, onde o pai ignora a mãe, mas se mantém infinitamente absorvido por sua filmoteca particular de anúncios.

\section{II}

Para DeLillo, a linguagem mostra-se sobretudo como uma ferramenta usada pelos discursos de poder. Em seu segundo romance, End Zone (1972), DeLillo diz que "começava a suspeitar que a linguagem era um assunto, assim como um instrumento em [s]eu trabalho". " Esse interesse tornou-se um método, de tal forma que alguns críticos têm se queixado que as personagens de DeLillo falam como se estivessem fazendo uma palestra, constantemente apresentando teorias, como Murray Siskind em White Noise. No entanto, embora DeLillo não tente fazer realismo ficcional, seu ouvido está admiravelmente afinado com o falar americano e, mais importante, teoricamente falando, ele costuma usar suas personagens como veículos para outras linguagens. Essa tendência é levada quase ao absurdo com os cientistas loucos de Ratner's Star (1976), que explora a linguagem não em relação ao silêncio, como em Great Jones Street (1973), mas em relação a códigos especiais e jargões de ciências e tecnologia. ${ }^{9}$

As idéias expressas pelas personagens de DeLillo não estão relacionadas a motivos psicológicos, nem são necessariamente coerentes com suas próprias ações, como o seriam na ficção realista. Os sujeitos individuais não são responsáveis por apreender ou criar, mas tendem a ser determinados pelos códigos que os controlam, tornando-se porta-vozes de idéias e, segundo Bakhtin, promovendo "inter-relações entre falas e linguagens": os romances de DeLillo não podem ser definidos pelas idéias realistas de mimese, mas pela heteroglossia, ou seja, a "multiplicidade de vozes sociais", e pelo "movimento do tema através de diferentes linguagens e tipos de discurso", que Bakhtin considerou como característico do romance. ${ }^{10}$ As linguagens especializadas e jargões profissionais entram em diálogo ou se chocam, como tão bem demonstra End Zone (1972).

8. LECLAIR 1982, p. 21.

9. JOHNSTON, 1989. p. 266.

10. JOHNSTON, 1989. p. 265; Bokthin, 1981. p. 263.
Todas as personagens de End Zone participam de jogos de linguagem, e o espírito ausente de Wittgenstein, na forma de um cartaz desaparecido, paira sobre o obscuro Logos College no deserto do Texas. Os jogadores de futebol americano se comunicam apenas através de "guerras de jargão"ll, usando não só a linguagem especializada dos esportes, mas também eloqüentes insultos e obscenidades, simplismos e clichês, além de "ferozes, estranhos ruídos" como uma espécie de "aquecimento psicológico" antes da partida. Um jogador faz seus comentários esportivos para uma televisão desligada; outro sugere que possa estar "falando em línguas". O protagonista propõe-se a dominar uma palavra nova e difícil todo dia e sua única aventura erótica acontece na biblioteca, onde se excita lendo um dicionário com sua namorada. $O$ mais curioso é que os jogadores recitam definições matemáticas ou científicas de palavras comuns que surgem na conversa, uma forma de comentário aparentemente irrelevante que serve para dar ênfase à estranheza da linguagem.

O protagonista Gary Harkness, jogador que ocupa a posição de meio de campo no time de futebol do Logos College, encontra-se afastado das escolas mais famosas, onde ele, por uma razão ou outra, não se encaixa. Em seu permanente estado de alienação, ele freqüentemente soa como o Meursault de Camus, mas, de forma tão irreverente quanto séria, Harkness vivencia sua própria variedade de linguagens: ele é freqüentemente irônico, ridicularizando pretensões e fomentando ambigüidades, porém, às vezes, parece apoiar e reforçar o reducionismo lingüístico e de comportamento promovido pelas autoridades. Entretanto Harkness constantemente se esforça para contestar esse reducionismo, como acontece quando se recusa a ser usado como propaganda por um publicitário recém-contratado, ou quando engana seus companheiros de time inventando histórias. $\mathrm{O}$ conceito que Harkness tem de Bobby Luke personagem que sustenta uma crença irrefletida no técnico, chegando mesmo a dizer que por ele "atravessaria uma parede de tijolos" - mostra uma consciência do perigo de tais formulas redutoras e sedutoras: "Talvez as palavras fossem encomendadas, como se diz, pela própria linguagem... cantigas de ninar processadas através de intricados sistemas... velhos e verdadeiros, cheios de confiança, conforto, consolo. Alguns homens seguiram tais palavras até à morte porque outros homens antes deles haviam feito o mesmo". ${ }^{12}$

Como líder supremo, o técnico Creed ("crença", em português) exige apenas obediência e assume a atitude superior de um monarca divino, fazendo

\section{LECLAR, 1982. p. 21.}

12. DEIIILO, 1986. p. 54. 
que seus assistentes técnicos se misturem aos jogadores, e os repreendam por suas falhas e imperfeições, enquanto do alto de uma torre de onde raramente desce, observa silenciosamente os modelos de jogadas. Sua autoridade vem dessa presença física, remota, porém visível, e de seu controle da palavra: "Este era seu poder: negar-nos as palavras de que precisávamos. Ele era um fabricante de jogadas, aquele que dá nomes."'3 Mesmo assim, como Harkness explica, o técnico não é realmente o tipo de criador divino que tais atributos sugerem: "todos os times fazem essas mesmas jogadas, mas cada time usa um sistema de denominação completamente diferente."14 A jogada chamada de "Blue turk right, double slot, zero snag delay", por exemplo, tem uma sonoridade original, quase poética, mas no contexto de um jogo funciona como uma ordem, exigindo uma obediência sem hesitação a um comportamento treinado e programado. Assim, o poder de Creed não se manifesta na criação, mas é implementado através da disciplina.

Nessa história, que LeClair chama de "fábula desconstrutiva""15, Logos sugere a centralidade da palavra. LeClair argumenta que Creed é a "voz primária do logocentrismo", cujo ideal é a metafísica da presença derridiana. Creed deseja um retorno ao "simples logos" do falecido fundador da Faculdade, um homem "que acreditava na razão", cultuando "a verdadeira palavra"16, mas que, de forma significativa, era mudo. Ao seguir esse objetivo, Creed fará a palavra tornar-se carne nos corpos de seus musculosos jogadores, pois sua crença na simplicidade, pureza e auto-conhecimento busca um retorno à "presença original".

Andando no deserto do Texas, "no meio do meio de lugar nenhum", um espaço reduzido às prioridades percebidas da presença, Harkness também expressa um desejo de imitar seu técnico, reduzindo um mundo por demais carregado de significado: "Começar a renomear o mundo já feito de excessos. Subtrair e separar. Recitar o alfabeto. Fazer as listas elementares." $\mathrm{O}$ romance mostra, assim, que, em resposta à limitação linear de Creed, "uma busca por uma auto-referencialidade e simplicidade lingüísticas leva a paradoxos insolúveis e a um reconhecimento de complexidade". ${ }^{8}$ DeLillo demonstra que os múltiplos

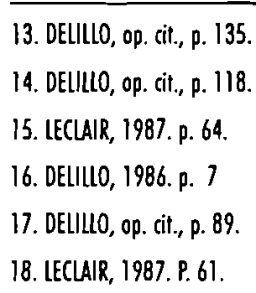

discursos e jogos de linguagem resistem a um "modelo monodiscursivo" desde "o início até o fim". ${ }^{19}$ O discurso patriarcal de autoridade, ao qual o pai de Harkness também se submete, não permite nenhuma liberdade com o contexto em que ele está encerrado. Na busca de Creed por pureza, o jogo não pode ser contaminado pelo mundo situado além dos limites do campo: "É só um jogo", diz ele, "mas é o único jogo".

O poder, de acordo com Bakhtin, tenta centralizar a linguagem em formas dominantes exclusivas. Na ficção, ao contrário, a linguagem deixa de ser uma "impermeável monoglossia" para se tornar uma "heteroglossia em formação" ${ }^{20}$ A necessidade de Creed de controlar o discurso é monológica e constitui uma negação de um diálogo: ela é o logos, a palavra de Deus, cujo "objetivo é transformar o time em ascetas presos à meta final", à imagem do próprio Creed. ${ }^{21}$

A linha de fundo é literalmente a área além da linha do gol, o alvo do jogo, um fechamento no sistema bastante demarcado do futebol. Contudo, como DeLillo demonstra, o futebol é apenas um dos jogos no romance, no qual "a ficção é ela própria um tipo de jogo". 22 Creed e Harkness, assim como muitas outras personagens nos demais romances, esforçam-se à sua maneira para simplificar discursos que competem entre si, transformando-os em uma narrativa única que caminha para a linha de fundo de fechamento total ${ }^{23}$ - Creed, através de um retorno ao simples logos; Harkness, por tentativas de simplificar drasticamente o significado e a escolha.

Bloomberg, amigo de Harkness, é um exemplo extremo desta tendência. Ele tenta "andar em uma linha perfeitamente reta", tornar-se um indivíduo de mentalidade direta, que visa a uma só finalidade, "começar tudo com sentenças simples, enunciativas". ${ }^{24}$ As consequiências são seu isolamento dos colegas e sua indiferença para com estes, seu desejo de ser "super-racional", de se "des-judaicizar" no Texas, livrando-se da culpa bíblica e dos pesos da História, ${ }^{25}$ e seu respeito e admiração pelo "planejador de sistemas", pelo
19. LECLAIR, op. cit., p. 71
20. BAKTHIN, 1981. p. 61
21. OSTEE, 1990. p. 148.
22. LECLAR, 1982. p. 21.
23. OSTEE, 1990. p. 144
24. DEllllo, 1986. p. 188.
25. DELIII0, op. cit., p. 46-47.

REVISTA DE ESTUDOS DE LITERATURA 
"consultor administrativo" e pelo "estrategista nuclear". ${ }^{26}$ Ao contrário, o professor Zapalac pode ser visto como o cposto radical de Creed, pois não se impõe e nem admira discursos monológicos. Como professor, ele não somente faz palestras, mas também faz piadas, perguntas, mistura-se aos alunos e geralmente procura nāo se mostrar uma figura de autoridade. Zapalac, que admite ser "um pouco paranóico", 27 explicitamente chama a atenção de seus alunos contra o estado militarizado. Ele chama os Republicanos do meio-oeste, entre os quais já havia trabalhado como professor, de "mestres de categorias de coisas", que foram "criados para acreditar em tudo que thes tinha sido dito pelos mais velhos": "Eles fazem as coisas em ordem alfabética. Eles sabem o seu lugar" ${ }^{28}$ Zapalac rejeita a ordem rígida do discurso patriarcal e autoritário em favor da "imprevisibilidade" e do "potencial para a desorganização inerente às pessoas e às coisas". ${ }^{29}$

O título End Zone faz também alusão à peça de Samuel Beckett, Endgame, especialmente a seu extremo niilismo e à discussão da morte. Essa linha de fundo é também o espaço terminal para o qual o slogan "Militarizar!", que Harkness uma vez vira pendurado ou impresso em todos os lugares em sua cidade natal, leva inexoravelmente a uma gradual crise política, a um mundo o começo dos anos setenta - onde as superpotências estão armadas num nível perigosamente alto. Embora sejamos levados a ver as simplificações de Creed, Bloomberg e Harkness como que saídas do mesmo impulso ascético, a visão de Harkness vai além do ascetismo redutor de seu técnico, que faz parte de sua própria vida e da vida de seu time. Harkness distingue-se das outras personagens por tentar levar sua visão a um nível planetário, uma visão fantasiada do apocalipse contemporâneo da guerra termonuclear, pela qual ele se torna obcecado. Harkness faz um curso de "tecnologia do desastre" e, embora se sentindo culpado, divertese lendo sobre desastres. Todo dia ele imagina uma cidade diferente sendo destruída, e sente "[p]razer na contemplação de milhões de pessoas morrendo e mortas",,$^{30}$ uma fantasia que lembra o prazer da família Gladney em ver desastres na TV em White Noise. Harkness parece compartilhar da fantasia bizarra contemporânea da purificação final da guerra nuclear, chamada por Robert Jay Lifton de extrema "solução para a angústia da morte"."

26. Ibidem. p. 49.
27. Ibidem. p. 183.
28. Ibidem. p. 164.
29. Ibidem. p. 163.
30. Ibidem. p. 21.
31. Apud OSIEEN, 1990. p. 152.

Harkness também se torna o melhor aluno de um curso sobre a guerra moderna concebido para oficiais estagiários da Força Aérea. Embora ofereça resistência a seu recrutamento para a ala militar pelo Major Staley, concorda em participar de um elaborado jogo de guerra nuclear com o Major no seu quarto de hotel no deserto, lugar onde geralmente são feitos testes nucleares. Como também observa Mark Osteen, o jogo de Staley baseia-se na situação de crise geopolítica planejada por estrategistas, tais como o "futurologista" dos anos sessenta Herman Hahn, cuja noção de "pensar o impensável" na verdade ajudou a fazer com que situações horríveis parecessem concebíveis e, portanto, quase aceitáveis. $O$ lingüista Noam Chomsky talvez tenha sido o primeiro a chamar a atenção para o modo como nossos líderes aprenderam a falar em público sobre cenários globais e estratégias operacionais. Em um de seus exemplos, ${ }^{32}$ o bombardeio de camponeses refugiados no Vietnã chega a ser descrito como "urbanização acelerada". Tanto os estrategistas militares do Pentágono, como os teóricos conservadores do tipo "think-tank" como Kahn, descrevem a guerra nuclear através de situações simuladas por computadores, uma prática e percepção que ajudam a disfarçar a realidade da morte e destruição em grande escala, talvez até o fim da vida presente e futura do planeta. "Slowmotion counter-city war, super-ready status, collateral destruction, civilian devastation attack" 33 são assuntos que Harkness delineia, enquanto "thermal hurricane, overkill, circular error probability, post-attack environment, stark deterrence, dose-rate contours, kill-ration, spasm war" tornam-se expressões pelas quais ele fica verdadeiramente fascinado. A mídia eletrônica, através de sua repetição de desastres, assassinatos e explosões acaba por fazer com que as pessoas aceitem facilmente a realidade de tais eventos. De maneira análoga, a linguagem especializada, o jargão curiosamente misterioso e impessoal da guerra nuclear, assim como sua familiarização através da repetição contribuem para obscurecer essas terríveis possibilidades.

A equivalência entre os jargões do futebol e da guerra nuclear, ambos discursos de poder, pode tornar-se um tanto simplista quando se considera o futebol como um tipo de guerra estilizada, ou uma manifestação do espírito de destruição americano. Como diz Zapalac, que também declara a Harkness adorar futebol: "Eu rejeito a noção de que o futebol seja uma guerra. Guerra é guerra. Não precisamos de substitutos porque o que temos é a coisa em si". A diferença crucial entre estes dois "jogos" é que o futebol é um ritual de violência que

32. Apud WILLIAMS, 1980. p. 13.

33. Esses termos fozem parte da linguogem militar especializada para se reterir ò guerro nucleor. 
pode ser jogado diversas vezes, enquanto a guerra nuclear é "sua terrível negação, um jogo que jamais poderá de fato ser jogado". ${ }^{34}$

Embora seja um jogo de sistemas em que jogadas pré-programadas são postas em prática por jogadores com tarefas definidas - ao contrário do futebol, no que jogadores devem reagir espontaneamente aos movimentos da bola - o futebol americano não é, afinal, um sistema fechado, já que os jogadores devem sempre levar em conta as ações de seus adversários, ao contrário do que faz o técnico Creed, que ignora os adversários de seu time. $\mathrm{O}$ desenvolvimento de uma jogada dependerá da reação de defesa do adversário, que, por sua vez, vai exigir uma resposta ou contramedida nem sempre planejada, até mesmo espontânea e individual, criando situações imprevisíveis. O sistema é fechado somente no sentido de estar confinado a um espaço limitado e funcionar de acordo com regras bem definidas. Apesar de o Major Staley sugerir que as guerras do futuro serão definidas, deste modo, inclusive com a presença de juízes, como em um jogo de futebol, é praticamente certo que não poderá contar com tais fatores limitadores da escalada de violência em uma situação política envolvendo bombas nucleares. A guerra nuclear, por definição, coloca a própria razão em xeque.

Por razões análogas, a linguagem não é, naturalmente, um sistema fechado. Na comunicação, uma fala exige uma resposta e, apesar da troca linguística estar sujeita a certas regras, ela continua a ser imprevisível. No romance, não é a violência da guerra e do futebol que provoca comparações metafóricas, mas suas linguagens. Através de sua linguagem e símbolos, o futebol cria uma ilusão de ordem em meio à reiterada violência física e ao caos no campo; os nomes das jogadas são interpretados cada vez que são colocadas em prática. A guerra nuclear, contudo, simplesmente empobrece a linguagem ${ }^{35}$; como Harkness diz ao Major Staley, "Não há jeito de expressar trinta milhões de mortos. Não há palavras. Então certos homens são recrutados para reinventar a linguagem". ${ }^{36}$

Como a estratégia nuclear, essa linguagem inventada é redutora e constitui-se de palavras criadas para resguardar os participantes da realidade: "Elas [as palavras] são analgésicos. Tudo se torna abstrato."'37 Apesar de Staley insistir na quase divina onipresença da bomba atômica, como Osteen aponta, esta escapa à metafísica da presença porque seu valor como arma depende de

$$
\begin{aligned}
& \text { 34. JOHNSTON, 1989. p. } 263 . \\
& \text { 35. JOHNSTON, op. cit., p. } 263 . \\
& \text { 36. DELILLO, 1986. p. } 85 . \\
& \text { 37. DELLLLO, op. cit., p. } 85 .
\end{aligned}
$$

nunca ser usada. Paradoxalmente, ela pode estar presente em nossas mentes somente enquanto estiver ausente, pois sua presença física asseguraria nossa total ausência. ${ }^{38}$ As "guerras de jargão" que DeLillo aplica a seus jogadores são empregadas por estrategistas para mascarar a realidade inominável de tal guerra. $O$ jargão em si torna-se uma arma, uma defesa lingüística, que inibe a reflexão sobre o que ele pode significar, ou uma tradução para "uma linguagem que é sempre insuficiente para representar uma condição na qual o significado está necessariamente ausente" porque seus usuários estão todos mortos. ${ }^{39}$

\section{III}

Em White Noise (1985), os dois espaços da experiência são o supermercado e a tela da televisão; que acabam se aproximando, uma vez que a integridade potencial da comida dá lugar aos ingredientes químicos nocivos, à embalagem festiva e aos chamativos anúncios de ofertas de supermercado. Tanto o supermercado quanto a tela de televisão oferecem representações, um tipo de linguagem visual, e são primordialmente lugares de desejo. No romance, a crítica cultural Murray Siskind afirma a plenitude de "dados psíquicos" tanto no supermercado ${ }^{* 0}$ quanto na televisãa $0^{41}$. Esta se faz ainda mais presente nesse romance do que em Americana, onde, na verdade, tudo é "mediado". O aparelho de TV da casa de Jack Gladney e sua familia encontra-se constantemente ligado, e por isso interrompe as conversas da família e até mesmo seus sonhos, como quando Gladney ouve sua filha murmurar "Toyota Celica" enquanto dorme. Ele percebe estar vendo suas crianças dormindo como "um momento de TV". Já o filho dele, Heinrich, joga xadrez por correspondência com um presidiário que matou cinco pessoas depois de ter ouvido vozes que lhe falavam diretamente da TV.

Uma das atividades favoritas da família Gladney é assistir a desastres tais como terremotos, incêndios, enchentes, explosões. Parece que a representação da morte na tela tem um poder curiosamente anestesiante, a mortalidade sendo reduzida a espetáculo. O perigo real em uma cultura de informação torna-se ilegível uma vez que os signos se tornam mercadorias. ${ }^{42} \mathrm{~A}$
38. OSTEEN, 1990. p. 151
39. OSIEEN, op. cit., p. 156
40. DELLLLO, 1985. p. 37.
41. DELILLO, op. cit., p. 51.
42. SHAPIRO, 1992. p. 129 
constante re-encenação da morte em massa serve para reduzir a ansiedade de Gladney, obcecado com a sua própria mortalidade, como mostra sua posição acadêmica de Chefe do Departamento de "Estudos Hitlerianos". Tais meios, porém, parecem ser ineficazes. O simples excesso de dados da cultura tecnológica- - TV, rádio, tablóides-não ameaça somente abafar o pensamento, mas também aponta para a presença da morte, como sugere o título do romance. A linguagem dessa cultura tende a tornar-se apenas ruído, processo entrópico de redução de significados à mesmice indiferenciada: "Será que a morte não é apenas um mero som... branco... uniforme". ${ }^{43}$

O recurso central do enredo é um desastre ecológico oficialmente chamado de "Evento Tóxico de Geração Aérea". "Precisamos ocasionalmente de uma catástrofe", um colega diz a Gladney, "para quebrar o incessante bombardeio de informação".44 O desastre é real, causando o deslocamento da familia e levando o próprio Gladney a ingerir uma dose potencialmente letal do gás tóxico. E, no entanto, o desastre pode ser vivenciado apenas como informação da mídia que, na cultura, define o real. O evento "se assemelhava a uma promoção nacional da morte, uma campanha multimilionária com apoio das estações de rádio, da imprensa e cartazes sensacionalistas, da saturação televisiva". ${ }^{45}$ Pode-se esperar, por exemplo, que o desastre cause sintomas médicos que seriam então registrados e divulgados, mas a filhas de Gladney continuam adquirindo os sintomas descritos nas transmissões anteriores de notícias. $O$ próprio fenômeno sofre uma transformação descritiva que altera sua realidade, passando de uma inocente "leve pluma" para uma terrível "ameaçadora nuvem negra" e chegando até sua denominação final, registrado por meio do eufemismo burocrático "evento de geração aérea". Como o autor explicou na entrevista, essa é uma linguagem que suprime a realidade enquanto ao mesmo tempo tenta fazê-la caber em um padrão formal.

As personagens de White Noise, como acontece em outros romances, vivem em um mundo de simulacros, em uma virtual "midiocracia"." Quando Gladney e Siskind vão ver "o celeiro mais fotografado na América", Siskind diz que é impossível vê-lo, uma vez que eles já possuem todos os "signos" referentes a ele: os sinais ao longo da estrada, as fotos, as inúmeras descrições. No entanto uma previsão contrária àquela feita por Walter Benjamin tornou-se

$$
\begin{aligned}
& \text { 43. DELILLO, 1985. p. } 198 . \\
& \text { 44. DELLLL, op. cit., p. } 66 . \\
& \text { 45. Ibidem. p. } 158 . \\
& \text { 46. CROWTHER, 1991. p. } 20 .
\end{aligned}
$$

realidade. A reprodução de representações não removeu a aura do autêntico, diz Siskind, mas ajudou a mantê-la: cada foto, na verdade, reforça a aura em diz percepção coletiva da qual não se pode fugir. A melhor demonstração da uma perace durante a evacuação depois do desastre. realidade superior do chamada SIMUVAC prepara a manobra, que, como Gladney aponta, afinal não é simulada, mas real. Um empregado responde que, na verdade, a organização pretende usar a evacuação real como "modelo", isto é, como uma oportunidade para ensaiar-se a simulação.

\section{IV}

Em alguns de seus romances-Players e Running Dog, ambos publicados na década de setenta, The Names, publicado na década de oitenta, e o recente Mao $I I$, de $1991-$, DeLillo explora as complexas relações entre política, em especial à política terrorista, as grandes corporações, a palavra escrita e oral e a midia. Um terrorista em Mao II, chamado Rashid, explica: "o terror é o que nós usamos para dar ao nosso povo seu lugar no mundo. O que costumava ser alcançado através do trabalho, passamos a conseguir através do terror $O$ terror torna o futuro possível. Todos os homens, um só homem. Os homens atualmente vivem na história como nunca o fizeram antes". ${ }^{47}$ Essa citação sugere o que é constante e explicitamente evocado no romance: uma ligação entre o romancista e o terrorista. A velha visão, encontrada em Henry James e Joseph Conrad, de que o terrorista é o alter ego do romancista ${ }^{48}$ é sugerida, em primeiro lugar, por George Haddad, intermediário dos terroristas no Ocidente, que diz ao escritor Bill Gray: "É o romancista que compreende a vida secreta". ${ }^{49}$ A sugestão repete-se através da fotógrafa e jornalista Brita, que, ao ser levada para fotografar c romancista Gray em seu esconderijo, sentese como se estivesse indo ao encontro de um líder terrorista.

Gray, um autor totalmente recluso como Thomas Pynchon, percebe que o poder que ele adquiriu através do anonimato deve-se principalmente ao desgastado e antiquado papel de artista romântico solitário que tem vivido ajudado por seu obsessivo assistente Scott. Gray mantém sua aura, na acepção de Benjamin, sendo único, não reprodutível. Idoso e incapaz de terminar seu

$$
\begin{aligned}
& \text { 47. DELLLD, 1991. p. } 235 . \\
& \text { 48. SCALAN, 1994. p. } 229 . \\
& \text { 49. DELLLO, 1991. p. } 158 .
\end{aligned}
$$


último livro, que vem revisando e reescrevendo por mais de vinte anos - talvez porque as palavras já não pareçam capazes de expressar a realidade -, Gray aceita ser fotografado, um ato que para Scott significa um meio de continuar cultivando a aura romântica, pois a imagem irá substituir o trabalho que Scott pensa que nunca vai ser concluído. Para Gray, a foto parece ser um reconhecimento de que aquele papel não é mais viável e que sua velha tarefa de criar ficções da "vida interior" não é mais relevante. No romance a imagem é emblema da onipresença da mídia, que parece mediar gradativament toda realidade. Os terroristas destroem o senso de subjetividade do poeta suíço raptado (a quem eles usavam exatamente para ganhar a atenção da mídia para sua causa), privando-o da experiência sensorial e recusando-lhe papel e lápis, através dos quais ele poderia reconstruir uma subjetividade com palavras. Enquanto isso, os terroristas, emblematicamente, assistem uma fita de vídeo; ao mesmo tempo, milícias em Beirute fazem um novo tipo de "combate" atirando nos cartazes illustrados com imagens dos líderes do grupo rival.

DeLillo mostra como as ações de terroristas tornaram-se afirmações eloqüentes das novas realidades políticas, à medida que a antiga relação do terrorista passa de alter ego a concorrente do romancista. Gray percebe isso quando sai de um anonimato consciente, adotando como princípio a frase " $O$ mundo das imagens é corrupto; eis aqui um homem que esconde sua face"so. Parte, então, para um reconhecimento rancoroso do poder da imagem: "Há a vida e há a transformação do acontecimento em mercadoria. Tudo em torno de nós tende a canalizar nossas vidas em direção a alguma realidade final, impressa ou filmada". ${ }^{51}$ Mas a velha ligação do romancista-terrorista com o rebelde solitário deu lugar "à dominação... da arte por pessoas violentas que manipulam a mídia" ${ }^{2}$, de tal forma que quase não se pode distinguir entre aqueles que carregam armas ou máquinas fotográficas. Num tipo de jogo "soma-zero", onde numa luta de poder um lado se beneficia com a perda do outro, Gray diz que a imprensa vem perdendo terreno para a imagem visual, que é o meio por excelência através do qual o terrorista faz seu pronunciamento: "O que os terroristas ganham, perdem os romancistas. $O$ grau em que influenciam a consciência de massa é a extensão de nosso declínio como formadores de sensibilidade e pensamento. $O$ perigo que estes representam equivale ao nosso fracasso em sermos perigosos". ${ }^{53}$ Gray considera Samuel Beckett "o último

\section{DELILLO, op. cit. p. 36.}

51. Ibidern. p. 43.

52. SCALAN, 1994. p. 241.

53. DELLLL, 199i.p. 157. escritor a moldar nosso modo de pensar e de ver. Depois dele, a tarefa mais importante envolve explosões em pleno ar e edifícios destroçados". ${ }^{54}$ Esta é a "nova narrativa trágica" do romancista pós-moderno, e talvez "o único ato significativo" em "sociedades reduzidas a obscurecer e saturar" " já que sensibilidades saturadas só reagem a declarações explosivas.

Entretanto, se DeLillo sugere o declínio do antigo poder da literatura de mudar consciências e influenciar os acontecimentos, ele também parece compartilhar da crença de Gray no forjar de palavras significativas para contrabalançar o poder de movimentos carismáticos e seus slogans simplistas. É assim que o próprio Gray responde aos argumentos "históricos" de Haddad:

Mesmo que eu pudesse ver a necessidade de uma autoridade absoluta, meu trabalho me levaria a um afastamento. A experiência de minha própria consciência me diz como a autocracia fracassa, como o controle total destrói o espírito, como minhas personagens vão contra meus esforços de possui-las completamente, como necessito de uma dissidência interna, uma discussão comigo mesmo, como o mundo me esmaga no momento em que eu penso que ele é meu. ${ }^{56}$

Esse não é meramente um apelo à integridade da consciência individual contra a realidade pública - Gray mostra-se um individualista radical, tanto na descrição de seu trabalho inicial como visão profundamente pessoal quanto na sua vida de voluntário isoladamente - mas também um alerta de que, em resposta às realidades do poder, a tarefa do escritor "depende do reconhecimento de que há uma vida da qual fazemos parte". ${ }^{57}$

Como aponta Margaret Scanlan, a questão do poder de a literatura mudar consciências recebeu grande atenção em 1989, apenas dois anos antes da publicação de Mao II. Esse foi o ano do massacre da Praça da Paz Celestial em Pequim e do funeral do Aiatolá Khomeini (ambos descritos no romance), eles próprios eventos de mídia e exemplos de apelos de massa de caráter emocional e potencialmente violentos, tanto da religião quanto da política. Naquele ano, ainda, o caso Salman Rushdie - no qual um romance (The Satanic Verses) foi tomado como ofensivo por certos membros devotos do Islamismo,

54. bidem. p. 157.

55. bidem. p. 157.

56. Ibidem. p. 159.

57. BRADBURY, 1991. p. $1127-28$ 
que puseram a cabeça do autor a prêmio por alegação de blasfêmia contra o texto sagrado islâmico e contra a família de seu fundador — parecia vir confirmar a alegação da ficção pós-moderna de participar da vida e transformar o mundo. ${ }^{58}$ A acusação de blasfêmia nas culturas liberais do Ocidente torna-se cada vez mais rara, pois a separação entre a Igreja e o Estado e as garantias constitucionais da livre expressão asseguram que quem for acusado de blasfêmia não pode ser legalmente processado. Além disso, como observou um crítico não ocidental, "a liberdade de expressão ocidental tem-se inscrito dentro de certos limites autogerados, idealizando a livre expressão mesmo quando esta interrompe a eficácia material da 'linguagem' no mundo". ${ }^{59}$ De modo semelhante, escritores ocidentais por vezes vêm expressando uma quase melancólica inveja de seus colegas nos antigos países comunistas do Leste europeu, onde um escritor poderia ser preso por se desviar da política ortodoxa. Tais eventualidades, embora desagradáveis ou até perigosas para o autor como pessoa, são um tributo às avessas, um reconhecimento do poder da palavra de perturbar, desafiar e subverter a ordem reinante e, assim, oferecer uma promessa de renovação. A simples existência da repressão é, sob este aspecto, uma garantia do poder da literatura.

Os muçulmanos fundamentalistas que fizeram manifestações contra Rushdie, queimaram seus livros, rotularam-no de infiel, exigiram seu assassinato e o condenaram a uma vida de exílio, de fato, com essas "afirmações" ativas não consideraram o romance de Rushdie "como um exercício imaginativo inconsequiente", apenas mais um texto pós-moderno capaz de causar admiração através da criatividade verbal e situações provocantes em leitores desgastados do ocidente, "mas como uma expressão poderosa de idéias profundamente vinculadas à realidade". ${ }^{60}$ Além disso, Gray reconhece que toda experiência quotidiana tem a tendência a tornar-se bem de consumo, o que também ocorre com o caso Rushdie. As demonstrações de protesto e queima de livros, até o anúncio público feito por Khomeini da fatwai ou execução justificada são eminentemente eventos de mídia. Nada realmente acontece na atualidade, a não ser que seja apropriadamente gravado em filme - fato que os romancistas podem lamentar, mas de que os terroristas estão conscientes. "O século vinte está em filme" ou "Este é o século filmado", como diz uma personagem em The Names. ${ }^{61}$ Assim, se os meios de comunicação determinam a existência, eles

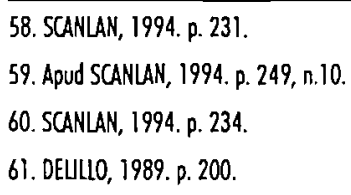

são duplamente poderosos, pois tanto podem criar realidades quanto torná-las inexistentes através de determinados silêncios. ${ }^{62}$

Se, entretanto, o romance reconhece o poder reduzido da literatura numa era da mídia, ele insiste na sua necessidade, uma necessidade reconhecida por Haddad, que pede a Gray que escreva algo monumental como o "livrinho vermelho" das máximas do presidente Mao, citado e exibido pelas massas chinesas, uma "experiência de Mao" que "se tornou incorruptível por forças exteriores", ou seja, um texto sagrado, "a narrativa imutável que toda a cultura precisa". ${ }^{63}$ A resposta de Gray a esse argumento é ao mesmo tempo prosaica "Não sou um visionário tão grande, George, só um fazedor de sentenças. Como um confeiteiro, só que mais devagar" ‘̛ _ _ e profunda — "Preciso de dissidência interna, argumenta". ${ }^{65}$

A resistência de DeLillo à totalidade e ao domínio das abstrações, à idéia a-histórica e mesmo sinistra de "narrativas imutáveis" toma a forma de uma percepção do romance como essencialmente ambíguo, cético e autoquestionador, um ponto de vista defendido pelo escritor tcheco Milan Kundera, pelo próprio Rushdie e por Bakhtin. ${ }^{66}$ Bakhtin teoriza o romance como discurso ao mesmo tempo critico e autocrítico. Se o poder tenta centralizar a linguagem em formas dominantes e exclusivas, a literatura subverte essa tentativa através do dialogismo de vozes múltiplas, de sua heteroglossia. Como afirmou o próprio Rushdie: "O romance tem sempre sido sobre o modo como diferentes linguagens, valores e narrativas entram em conflito e sobre as relações em constante mudança, que nada mais são que relações de poder." ${ }^{67}$ Quanto a DeLillo, este parece falar através de Gray, que, em seus últimos momentos de vida, reflete sobre um poeta europeu, mantido como refém de terroristas:

Quando se pune alguém que não é culpado, quando se enchem celas com vítimas inocentes, começa-se a esvaziar o mundo de significado e erigir um estado mental separado; a mente passa a consumir o que está fora de si mesma, e a substituir coisas reais por enredos e ficções. Uma ficção fechando o mundo para dentro de si mesmo, outra empurrando-o para
62. GUARESHI et olii., 1991. p. 14.
63. DELLLO, 1991. p. 162
64. Ibidem. p. 162
65. Ibidem. p. 159.
66. SCALAN, 1994. p. 241
67. RUSHDIE, 1990. p. 102-103. (êntose minho) 
fora da ordem social, tentando abrir-se para ele... É assim que respondemos ao poder e suplantamos nosso medo. Aumentando o grau de consciência e possibilidade humana.. ${ }^{69}$

\section{$\mathbf{V}$}

A linguagem é o foco central de The Names (1982) e, como em End Zone, pode servir como meio de dominação; já em Mao II, a linguagem apresenta seu lado positivo por indicar uma possibilidade em aberto, constituindo uma arma contra o terrorismo. Neste romance, por exemplo, a linguagem mostra-se através do poder comunicativo do diálogo, questão que é demonstrada pelos atenienses, entre os quais o protagonista James Axton vive. Este chama a atenção para o longo tempo dedicado pelos atenienses: "conversar é viver, a linguagem o ser mais profundo... A conversa flui incondicionalmente, os participantes mergulham nela completamente". ${ }^{69}$ A própria presença de Axton constitui, ao mesmo tempo, um exemplo da função da criatividade e também do reducionismo, ao observar que os americanos antigamente iam à Grécia para escrever e pintar, porém, agora, preocupam-se apenas em fazer negócios. ${ }^{70}$ É importante ressaltar que Axton possui apenas noções rudimentares de grego, o que faz com que ele se sinta como um turista.

Esse outro lado da linguagem também fica evidente nas profissões de Axton e seus companheiros. Citando Walter Ong e sua análise de sociedades em diferentes estágios de escrita, LeClair afirmou que DeLillo está enfatizando "o preço da escrita" "11 uma situação que contrasta com o valor dado à oralidade por gregos tão comunicativos. Tal interpretação pode sugerir o que Derrida aponta criticamente como a nostalgia pela presença da palavra falada em lugar da letra morta. Apesar disso, a escrita certamente tem seu lugar: a tecnologia da imprensa é dominada pela visão, e não pelo som; ela mais "isola e fragmenta" do que "incorpora e unifica", estimulando as qualidades de "distinção e análise, originalidade, abstração, distanciamento, absolutismo, e possível capacidade autodestrutiva", 72 qualidades evidentes tanto nas personalidades e profissões

\footnotetext{
68. DELILLO, 1991. p. 200.

69. DELILLO, 1989, p. 52.

70. DEULLO, op. cit., p. 6.

71. LECLAIR, 1987. p. 191

72. LECLAIR, op. cit., p. 190-191
}

dos banqueiros multinacionais e homens de negócios apresentados nos romances, quanto nas ações assassinas da seita bizarra que Axton fica conhecendo.

O próprio Axton começou como escritor de "lixo institucional" de corporações e governos, como alguém que, de forma alienada, não se preocupa com o conteúdo, limitando-se a corrigir erros sintáticos e estilísticos do discurso. Sendo um escritor free-lancer, ele parecia estar ainda mais distante da responsabilidade pelo que escrevia, mas agora ele se encontra totalmente inserido na estrutura da corporação como um "analista de risco" na Grécia para o grupo multinacional Northeast, para quem ele não mais escreve, mas apenas lê relatórios e transmite mensagens de telex. Tipo clássico do "estrangeiro inocente", ele é um empregado dedicado, embora ocasionalmente com senso crítico, que se sente traído quando eventualmente toma conhecimento de que sua companhia tem conexões com a CIA, o que faria com que ele estivesse indiretamente envolvido em espionagem. Seu trabalho consiste em revisar reportagens e análises para determinar o que "parece provável" nas instáveis nações do Oriente Próximo: "Colapso, deposição, nacionalização? Talvez um problema de balanço de pagamentos, talvez corpos jogados nas valas. Qualquer coisa que ponha em risco um investimento". ${ }^{73}$ A ironia dessa sentença pode ser medida quando o grego Elíades lhe diz que os americanos aprendem sobre outras países somente quando seus interesses vitais são ameaçados, interesses que não têm nenhuma relação com as necessidades desses países, pois seus governos parecem basear-se no princípio do "Tome o dinheiro dos americanos. Faça o que os americanos nos disserem para fazer". ${ }^{74} \mathrm{~A}$ ingenuidade de Axton consiste no fato de ele achar que a informação que consegue de fontes públicas e privadas e que analisa para a companhia não têm consequiências políticas nocivas, que a informação é, de alguma forma, independente do poder, ou que os campos econômico e político operam independentemente.

Em oposição ao diálogo tão comum entre o povo grego, as empresas dependem de análises estatísticas e relatórios abstratos unilaterais, informação reunida não através de interação mútua e voltada para o benefício de todos, e visam, secretamente, a fins lucrativos. $O$ romance sugere que a análise dos documentos e estudos do projeto neocolonialista dos homens de negócios e banqueiros é análoga ao trabalho lingüístico do estudioso da escrita, o inglês Rawlinson, que decifrou a escrita cuneiforme: "encaixar os elementos de um padrão", achar uma "linha" que explique informações que, caso contrário, seriam

$$
\text { 73. DELULL, 1989. p. } 34 .
$$$$
\text { 74. DELILLO, op. cit., p. } 235 .
$$ 
variadas e confusas. Assim, o objetivo seria "dominar e codificar"' - talvez um lema virtual do colonialismo. Fica clara a relação de tal atividade científica no colonialismo, "o lado científico do imperialismo", quando Axton comenta que os estudiosos da escrita britânicos eram de fato empregados da Companhia das Índias Orientais. Instrumento importante do imperialismo britânico no Oriente, essa organização conseguiu dos imperadores locais privilégios de comércio excepcionais para a coroa britânica, e, quando o poder desta declinou, tal fato teve consequiência direta nos negócios na Índia. Como Pynchon, DeLillo questiona a estreita colaboração entre a ciência e os negócios - tanto a pesquisa técnica quanto as propriedades codificadoras da linguagem - em uma cultura de morte: "Os técnicos são os invasores de sociedades antigas. Eles falam uma linguagem secreta. Trazem novos tipos de morte consigo". ${ }^{76}$ De sua parte, Axton se diverte com o "linguajar técnico" de seus companheiros, o vocabulário especializado de banqueiros estrangeiros, homens de negócios e especialistas, que reflete o poder das instituições que os empregam."

Os antigos expatriados de formação humanística que buscavam inspiração para sua criação artística em sociedades antigas deram lugar a esses novos tipos de agentes temporários das corporações multinacionais, tanto europeus quanto norte-americanos, mas "servindo aos mesmos objetivos"..$^{78} \mathrm{O}$ resultado é a formação de "uma subcultura, negociantes em trânsito, envelhecendo em aeroportos e aviōes". 9 O chefe de Axton, Rowser, mostra-se um exemplo do ponto de vista apolítico e voltado exclusivamente para o lucro desses servidores multinacionais, quando ele cita palavras de seu próprio superior: "O poder funciona melhor quando não distingue amigos de inimigos". ${ }^{\text {.0 }}$

As corporações, no entanto, devem levar em consideração a política local e nacional a fim de proteger tanto os investimentos quanto o pessoal. $O$ período é o fim dos anos sententa, durante a revolução iraniana, uma situação que faz com que essas pessoas, temerosas com a situação dos reféns americanos em Teerã, queiram fixar residência em uma área menos instável como a Grécia. Contudo, sua segurança pessoal pode ser comprometida por terroristas nacionalistas. Conseqüentemente, Rowser torna-se obcecado pelo sigilo: sua vida está "cheia dos ornamentos da paranóia e do engano"»l , e não é à toa que vida está "chvolve com a CIA, "aquela fantasticamente descentralizada, quase autônoma disseminação de informação errônea, paranóia e terror". ${ }^{22}$ Como Axton observa, "Se a América é o mito vivo do mundo, então a CIA é o mito da América. Todos os temas estão lá, em camadas de silêncio, burocracias inteiras de silêncio, em conspirações e... brilhantes traições". ${ }^{83}$ Uma das funções míticas da CIA é que "nos permite participar de um espetáculo de violência", pois ela "produz muito da violência que a justifica"'s4, como se vê no final do romance.

O trabalho de Rowser é vender seguro de risco, ou seja, resgate, a executivos de multinacionais sujeitos a sequiestros. Para isso, Rowser possui "toneladas de material de pesquisa sobre o valor desses seguros" ${ }^{85}$; porém, esse seguro não contribui para de fato deter o terror ou reduzir o risco. Axton, o analista de risco, é, portanto, uma espécie de "parceiro silencioso" do terrorismo, uma vez que é ele que calcula seu significado. ${ }^{86}$ A precariedade dos serviços prestados à estrutura das corporações multinacionais mostra-se no romance quando o banqueiro Keller é baleado enquanto corre no parque. Axton, que testemunha a ação, fica sem saber se a bala fora talvez destinada a ele próprio. A ambigüidade do alvo humano mostra o pacto entre governo e capital, bem como a natureza impessoal do ato terrorista.

O preço da escrita também afeta personagens mais simpáticos, como Owen Brademas, ele próprio um leitor de inscrições, ou seja, aquele que faria as pedras antigas "falarem". No entanto o estudo das inscrições constitui uma forma de comunicação unilateral com os mortos, e Owen finalmente admite que acha as letras mais interessantes em si mesmas do que como signos de culturas antigas. Owen é, por exemplo, indiferente à escavação arqueológica que supervisiona numa ilha grega, e, quando vai para a Índia ler um épico sânscrito nas paredes de uma ruína, contenta-se em meramente admirar a escritura. Ele conta estórias e fornece análises culturais intrigantes, mas estas são apresentadas em monólogos que inibem qualquer diálogo. Durante um de seus longos discursos sobre a linguagem, por exemplo, Axton se perde num devaneio de caráter erótico com a figura de sua mulher, que estava no quarto ao

$$
\begin{aligned}
& \hline \text { 81. Ibidem. p. } 44 . \\
& \text { 82. FOSTER, 1991. p. } 157 . \\
& \text { 83. DELILL, 1989. p. } 317 . \\
& \text { 84. FOSTER, 1991. p. } 162-163 . \\
& \text { 85. DELILL, 1989. p. } 46 . \\
& \text { 86. FOSTER, 1991. p. } 161 .
\end{aligned}
$$


lado. A procura obsessiva de Owen por escrituras esotéricas parece indicar um desejo de alcançar algum significado definitivo, uma errônea crença na capacidade da linguagem de finalmente explicar o mundo. ${ }^{87}$ A questão é que não mais vivemos em um mundo que possa ser compreendido, não importa qual seja nossa inteligência, obsessão ou necessidade.

A experiência mais traumática da infância de Owen aconteceu em Kansas, quando testemunhou um pregador incitando seus paroquianos a falarem "em línguas", um falso exemplo de reciprocidade de linguagem na comunidade, pois as línguas eram uma fala ininteligível. Mas o que o incomodava particularmente era sua incapacidade de participar desse ritual, de "soltar" sua língua. Este episódio está reproduzido no final do romance, em um capítulo do "romance de não-ficção" que está sendo escrito por Tap, o precoce filho de Axton. Nele, o alter ego de Owen não cede à glossalalia de seus vizinhos. As incorreções ortográficas do texto e os empregos errôneos de palavras sugerem não só o falar dos jovens mas também o estilo de Joyce, suas brincadeiras e jogos de palavras - um estilo vedado a Owen, devido a seu temperamento excessivamente analítico, como ele confessa a Axton.

Owen descobre nas colinas gregas uma bizarra seita de adoração do alfabeto - "os abecederianos" - que se transforma em uma linha da trama não resolvida. Um guia tenta explicar o fascínio da seita pelo alfabeto: "O alfabeto é masculino e feminino. Se você souber a ordem correta das letras, você pode fazer um mundo". ${ }^{88}$ Mesmo assim, a seita procura uma ordem, uma "lógica", através do assassinato sem sentido, numa versão lingüísticamente motivada da "família" criminosa de Charles Manson na Califórnia. Os membros da seita selecionam uma vítima no local onde estão morando, alguma pessoa mental ou fisicamente deficiente, cujas iniciais combinem com a primeira letra de cada palavra do nome do local, e esculpem ou gravam as iniciais no instrumento usado para a prática ritual, o que se relaciona mais com o vodu ou a magia do que propriamente com a linguagem real. Sua escolha de vítimas marginais sugere que os membros da seita se acham excessivamente preocupados como o estabelecimento de uma ordem em um mundo imperfeito. Eles retiram palavras da lógica, como, por exemplo, "premissa" ou "válido/a" a , e se chamam "iniciantes", como se estivessem procurando uma nova visão, no que se parecem com o técnico Creed de End Zone e outros mal direcionados simplificadores da

87. BRYANT, 1987. p. 22.

88. DELLLO, 1989. p. 152.

89. DELILLO, op. Cit., p. 302. complexidade do mundo. Como um dos seus porta-vozes diz ao explicar porque ele passou a fazer parte da seita: "Me pareceu certo... Números se comportam, ele paras não". ${ }^{90}$ Os "textos" da seita são suas vítimas sobre as quais as palavras não" ibstratas de letras distintas são inscritas. A referencialidade foi substituída pela mera combinação e pela reciprocidade de comunicação com uma ordem imposta, unilateral. ${ }^{\text {.1 }}$

O nome secreto do culto pode ser o "Ta Onamata" (Os Nomes), como Axton descobre por essas palavras pintadas numa pedra do Mani, nas montanhas, um lugar habitado pelo culto, onde um membro lhe diz que "e possível para os homens pararem de fazer história. Já foi inventada uma saída". " Para tentar escapar da história pelo assassinato, "reificar o ato de matar em um último artefato da fúria contra a inconsistência do desconhecido"”, é um exercício fútil, como um outro membro parece reconhecer no final, quando a seita parece praticamente ter se extinguido: "O mundo se tornou auto-referente... um mundo no qual não há escapatória" ".4 Assim, a sequiencialidade, análise, originalidade, abstração, separação, absolutismo, e possível auto-destruição da alfabetização são características que são preenchidas nos atos de extermínio do culto e seu próprio fim.

Owen deixa o culto para se retirar em um quarto pequeno em Lahore, axton o acha e o incita a lhe contar a história, aliviando, de uma certa maneira sua culpa, através da comunicação oral. O "modelo" e a "diretriz" procurados pelas multinacionais para seus próprios fins são evidentemente um atributo da própria escrita, ou antes, o tipo de escrita na qual a conexão com uma história social em curso ou já vivida tem sido negligenciada ou abolida. Isto é assinalado primeiro no caso de Owen, quando admite a Axton que perdeu seu antigo interesse acadêmico em culturas antigas, mas agora vê "uma importância misteriosa nas letras como tais" "95, isto é, como meras personagens removidas de qualquer contexto humano. Como um membro do culto aponta, "caracteres" em grego têm o significado de "lâminas", ou seja, a palavra faz referência ao ato de inscrever ou gravar, porém aqui, naturalmente, representa matar brutme mortos;
90. Ibidem. p. 108 .
91. LECLAR, 1987. p. 192.
92. DELlLL, 1989. p. 209.
93. BRYANT, 1987. p. 19
94. DEULLO, 1989. p. 297.
95. DEEllLO, op. ait, p. 35 . 
eles estão vivenciando a morte, o que pode ser visto quando o culto realmente se dá ao ato de matar, durante o qual eles não proferem palavras, mas emitem somente sons inarticulados e gritos e suas armas ou instrumentos ressoam como roucas batidas rítmicas. A sua "forma subverbal de conexão é a violência", a qual é discreta, isolada e ocasional" como as comunicações das multinacionais, com as quais eles compartilham "uma necessidade de estarem desconectados das ambigüidades da linguagem falada".96

O progresso de Axton através do romance pode ser lido como uma experiência de aprendizagem lingüística. Ele parte de uma posição de escravo de êxtase da linguagem do mundo das corporações para uma gradual compreensão da artificialidade da linguagem e um entendimento de que as palavras podem ser regeneradas e re-combinadas afim de se renovarem ${ }^{97}$ uma conclusão que depende da percepção de que a linguagem, enquanto meio de interação social, não é fixa, mas fluida por natureza. Axton mostra essa nova atitude quando questiona as análises de Owen ou resiste a elas, quando se recusa a ser o mero escritor-arquivista da seita e seduz a mulher de um banqueiro, unindo o discurso e a linguagem corporal, nomeando as partes do corpo como um prelúdio à combinação física destas. Quando, perto do fim, Axton se pergunta como conectar coisas, ele próprio responde: "Aprenda seus nomes". ${ }^{98}$ Os nomes não se tornam significantes distintos e vazios, mas dissolvem-se em sua função conectiva, uma maneira tanto de criar quanto de compartilhar o sentido.

$O$ aspecto vivo da linguagem, em oposição à morte do ritual vazio, é ilustrado na visita final de Axton e também sua última visão da Acrópole, o monumento a uma civilização desaparecida que, no começo do romance, ele evitara por considerá-la uma abstração a-histórica e pura, algo por demais "exaltado", um análogo de sua percepção anterior da própria linguagem. Quando Axton finalmente sobe ao templo, este perde sua brilhante gloria, fazendo com que ele chegue à conclusão de que não se trata de "uma relíquia da extinta Grécia, mas parte da cidade que vive abaixo dele". Multidões de visitantes entram no templo falando as mais variadas línguas: "Isto é o que nós trazemos ao templo; não trazemos orações, nem cânticos, nem cordeiros sacrificados. Nossa oferenda é a linguagem". ${ }^{100}$ Axton se vê perplexo frente às inspiradas transformações do inglês cotidiano de seu filho Tap: "Achei essas palavras 作 mutiladas espantosas. Ele as tinha renovado, e me realmente eram. Eram coisas antigas, secretas, remoldáveis". ${ }^{101}$

A linguagem, embora antiga, é sempre passível de renovação, lição que Axton leva consigo em sua nova "visão" do Partenon. Não é somente a comunicação oral que está viva, afinal de contas; a escrita também pode ser infinitas vezes moldada, e assim re-escrever a realidade. Na verdade, é assim que deve acontecer, pois, segundo Bryant, "a vida de um indivíduo na linguagem não é uma tabula rasa, mas um palimpsesto, já re-escrito e borrado por contatos anteriores". ${ }^{102}$ As palavras revelam uma textualidade inerente e uma saudável "desarrumação" que sempre lembram suas origens e sua gradual evolução ao longo do tempo através do uso social.

\section{ABSTRACT \\ This article analyzes several texts of the contemporary novelist Don DeLillo, whose work Paul Auster says is necessary for the understanding of American society at this end of the century. What is emphasized here is the nature of the author's themes and their relevance for a globalized world: military power, terrorism, the power of capital, and especially the hegemony of the languages of power and the resistance to them.}

KEYWORDS:

Fiction, Power, Terrorism, Languages

\section{LECLAIR, 1987. p. 193. \\ 97. BRYANT, 1987. p. 18. \\ 98. DEULL, 1989. р. 328. \\ 99. DELlll0, op. cit., p. 330}

100. bidem. p. 331.
101. Ibidem. p. 103.
102. BRYANT, 1987. p. 26.

REVISTA DE ESTUDOS DE LITERATURA Belo Horizonte, v. 5, p. $69-94$, out. 97

[9] 


\section{A TECITURA DO SILÊNCIO NA NARRATIVA DE GRACE PALEY}

REFEREANCIAS BIBUOGRÉFICAS

BAKHTIN, M.M. The Diologic Imogination: Four Essoys. Ed. Michoel Holquist. Austin: University of Texos Press, 1981. BRADBURY, Malcolm. Neored is Fiction. Columbio History of the Americon Novel. New Yolk: Columbio University Press, 1991.

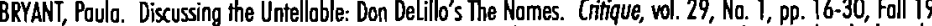

CROWTHER, Hol. Clinging to the Rock. A Novelist's choices in the New Mediocrooy. Lentricchio, Frank, ed. Introducing Don Delillo. Durhom: Duke Universily Pless, 1991, pp. 83-98.

DECURTIS, Anthany. An Outsider in this Society: An Interview with Don Debillo.

Lentricchio, Frank, ed. Introducing Don Delillo. Durham: Duke University Press, 1991, pp. 43-66.

. End Zone. 1972. New York: Penguin, 1986.

- Moo Nil. New Yoik: Penguin, 1991.

The Nomes. 1982. New York. Vintoge,
Running Dog. New York: Knopf, 1978.

_- Running Dog. New York. Knopf, 1978.

FOSTER, Dennis. Alphobetic Pleosures: The Nomes. Lentricchio, Fronk, ed. Introducing Don Delillo. Durhom: Duke University Press, 1991, 157-173.

GUARESCHI Pedrinho, et olii. Comunicoröo e Controle Sociol. Petropolis: Vozes, 1991

JAMESON. Frederic. Review of The Nomes Minnesoto Review no. 22, pp. 116-122, Spring 1984

JOHNSTON John. Generic Difficulties in the Navels of Don Dolillo. Critique, vol. 30, no. 4, pp. 261-275, Summer 1989.

KELLNER, Douglos. Jeon Boudrillord: From Moxxism to Postmodernism ond Beyond. Stonford: Stonford University Press, 1989

IECLAR, Tom. An Interview with Don Delillo. Confemporary Literoture, vol. 23, no. 1, pp. 19-31, Winter 1982.

-. In the Loop: Don Delillo ond the Systems Novel. Urbano: University of illinois Press, 1987.

IENTRICCHIA, Fronk, ed. Introducing Don Deullo. Durhom: Duke University Press, 1991

MCCLURE, John. Postmodern Romence: Don Delillo and the Age of Conspirocy.

Lentrichio, Fronk, ed. Introducing Don Delillo. Durhom: Duke University Press, pp. 99-115.

MORRIS, Mothew. Murdering Words: Longuoge in Ation in Don Delillo's The Nomes. Contemporony Literofure, vol. 30, no. I, pp.

OSTEEN, Mark. Agoinst the End: Asceticism ond Apololypse in Don Delillo's End Zone. Popers on Longuage ond Literoture, vol. 26, POSTER no. 1, pp. 143-163, Winter 1990 .

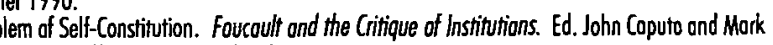
Yount. University Pork: Penn State Univessity Press, 1993.

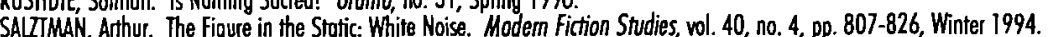
SCAMLAN, Margoret. Writers Among Terrorists: Don Delillo's Moo Il and the Rushdie Affair. Madem Fiction Studies, wol 40, no. 2

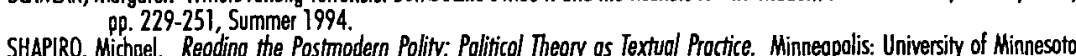
Press, 1992

WILLIAMS, Roymond. Problems in Moteriolism and Culture: Selected Essoys. London: Verso, 1980.
Suely Maria de Paula e Silva Lobo

$P U C-M G$

\begin{abstract}
Ouve-me, ouve meu silêncio. $O$ que falo nunca é o que falo e sim outra coisa. ... Capta essa outra coisa de que na verdade falo porque eu mesma não posso.
\end{abstract}

Clarice Lispector (Água viva)

\section{RESUMO}

Este trabalho procura demonstrar a maneira como a escrita de Grace Paley, autora americana contemporânea, joga com o silêncio e o não-dito para denunciar e desconstruir falsos valores sobre os quais se estruturam determinados construtos sociais.

PALAVRAS-CHAVE:

Grace Paley, silêncio, máscara, voz.

Falemos, aqui, de silêncio, pois esse é um modo eficaz de tentar ouvilo, de tentar compreender, através de suas múltiplas facetas, a potencialidade de expressão que nele subjaz.

E ninguém melhor que Grace Paley para deixar-nos vislumbrar essa riqueza de linguagem. Paley, com sua escrita fragmentada, descontínua e que, freqüentemente, privilegia vozes intermitentes e ambíguas em detrimento de outras, fluentes e claras, reina, poderosa, nesse campo de expressão. Quatro 